\title{
Screening for Anticancer Activity of Leaf Ethanolic Extract of Alpinia elegans ("tagbak") on Human Cancer Cell Lines
}

\author{
Ryan C V Lintao, Paul Mark B Medina*
}

\begin{abstract}
Background: Lung, liver, and colorectal cancers are among the leading causes of cancer-related deaths in the Philippines. As chemotherapeutic treatments remain expensive, native plants are being studied as alternative treatments for use in primary care. In this study, Alpinia elegans leaf ethanolic extract ("tagbak," TGK) was screened for potential anti-cancer activity against lung (A549), colorectal (HCT116) and liver (HEPG2) cancer cells. Methods: An ethanolic extract (TGK) was prepared from A. elegans leaves sampled from Infanta, Quezon. Its anti-proliferative activity on A549, HCT116 and HEPG2 was determined using MTS cell viability assay, with doxorubicin (DXR) as positive control and $0.1 \%$ DMSO in culture media as negative control. To differentiate cytostatic from cytotoxic effects, LDH cytotoxicity was performed, with 5-fluorouracil (5-FU) as positive control. In screening for metastatic potential, scratch wound assay was done, with percent gap closure as indicator of cell migration. To visualize the actin filaments and nuclei, the cells were stained with AlexaFluor488-tagged phalloidin and Hoechst 33342, respectively. Results: Phytochemical analysis revealed traces of alkaloids, moderate amounts of sterols, and abundant triterpenes, flavonoids, saponins, glycosides and tannins in TGK. TGK exhibited anti-proliferative activity at high concentrations, with TGK being more effective against HEPG2 ( $\left.\mathrm{IC}_{50}: 98.35 \mathrm{ppm}\right)$ than $\mathrm{A} 549\left(\mathrm{IC}_{50}: 245.5 \mathrm{ppm}\right)$ and HCT116 $\left(\mathrm{IC}_{50}: 299.7 \mathrm{ppm}\right)$. This can be attributed to the cytotoxic activity of TGK as seen in LDH release assay, with HEPG2 more affected than HCT116 or A549. TGK also attenuated cell migration, with significantly different gap closure from negative control at 500 ppm $(\mathrm{p}<0.05)$. Cytoskeleton and nuclei visualization via fluorescence microscopy showed cell shrinkage and pyknosis, as well as cellular debris, indicating both apoptotic and necrotic effects on cancer cells. Conclusion: The ethanolic leaf extract of Alpinia elegans significantly inhibits cellular proliferation and migration at high concentrations, with direct exposure-response relationship within concentrations.
\end{abstract}

Keywords: Anti-cancer- Alpinia elegans- cell proliferation- cytotoxicity- cell migration

Asian Pac J Cancer Prev, 22 (12), 3781-3787

\section{Introduction}

The global burden of cancer is estimated to have risen to 18.1 million new cases and 9.6 million deaths in 2018, with $48.4 \%$ of the new cases and $57.1 \%$ of cancer-related deaths coming from Asia (International Agency for Research on Cancer, 2018). In the Philippines, cancer is the third leading cause of mortality, with lung, liver, and colorectal cancer among the most commonly diagnosed and the leading cause of deaths due to cancer (Laudico et al., 2015). Despite available therapeutic modalities such as surgery, radiotherapy and chemotherapy, treatments remain expensive and inaccessible. Herbal medicine remains to be the most accessible form of healthcare with more than $80 \%$ of the world's population using traditional medicine in primary health care (World Health Organization, 2004), and recently there has been growing interest in studying medicinal plant extracts for anticancer activities.
Alpinia elegans K. Schum (Family Zingiberaceae), more commonly known as 'tagbak', is an endemic species of herbaceous plant found in thickets along streams at low to medium altitudes in Luzon, Polilio Islands, Mindoro, and Leyte. A. elegans is a medicinal plant with known folkloric uses such as rhizome decoction for hemoptysis, pounded leaves mixed with little salt for paralyzed extremities, and juice from macerated young stems for urticaria (Quisumbing, 1978). It has also been shown that $A$. elegans has antimicrobial properties (Oliveros and Bruce, 1991). Despite many studies showing anticancer properties of various Alpinia species (Malek et al., 2011; Reddy et al., 2013; Samarghandian et al., 2014; Afshari et al., 2008), there are no published studies on possible anticancer activity of $A$. elegans leaves.

In this study, leaf ethanolic extract from Alpinia elegans (TGK) was screened for potential anti-cancer activity against human lung epithelial (A549), colorectal (HCT116) and hepatocellular cancer (HEPG2) cells. 
Anti-proliferative and cytotoxic activities of TGK were assessed via MTS cell proliferation assay and LDH cytotoxicity assay, respectively. In addition, the effect of the extract on cell migration was investigated via in vitro scratch wound assay. Fluorescence microscopy was done to visualize the effect of TGK on gross cellular and nuclear morphology.

\section{Materials and Methods}

\section{Study design}

The study was implemented using a post-test only control group design. This was registered under Research Implementation and Development Office (RIDO) and Research Grants Administration Office (RGAO) of University of the Philippines Manila, and was exempted for ethical review by the Research Ethics Board of the same institution.

\section{Preparation of Alpinia elegans leaf ethanolic extract (TGK)}

Mature, undamaged A. elegans leaves $(4.5 \mathrm{~kg})$ were collected from Infanta, Quezon Province, and were authenticated by a botanist from Museum of Natural History in University of the Philippines Los Baños. Each leaf was garbled and rinsed thoroughly with distilled water, and the leaves were airdried in a clean, well-aerated room for one month. The dried leaves were pulverized using Wiley mill and soaked in 95\% ethanol for 48 hours. The mixture was filtered, and the filtrate was concentrated using a rotary evaporator at $60^{\circ} \mathrm{C}$ under vacuum for 3 hours. A sample of TGK was sent to Industrial Technology Development Institute, Philippine Department of Science and Technology for qualitative phytochemical analysis.

\section{Cell lines and cell culture maintenance}

Homo sapiens cancer cell lines A549 (lung epithelial), HCT116 (colorectal) and HEPG2 (hepatocellular) (ATCC) were maintained at National Institute of Molecular Biology and Biotechnology, University of the Philippines Diliman. A549 cells were cultivated in Dulbecco's Modified Eagle Medium (Gibco, Life Technologies) with 10\% fetal bovine serum (Gibco, Life Technologies) and 1X penicillinstreptomycin (Gibco, Life Technologies), HCT116 in RPMI 1640 Medium (Gibco, Life Technologies) with $10 \%$ fetal bovine serum and $1 \mathrm{X}$ penicillin-streptomycin, and HEPG2 in Minimum Essential Medium (Gibco, Life Technologies) with $10 \%$ fetal bovine serum and $1 \mathrm{X}$ penicillin-streptomycin, all in $25 \mathrm{~cm}^{2}$ cell culture flasks (Corning). The cell cultures were incubated at $37^{\circ} \mathrm{C}$ in a humidified atmosphere of $5 \% \mathrm{CO}_{2}$, and were subcultured every 3 days at $80-90 \%$ confluence.

\section{Cell proliferation assay}

The anti-proliferative activity of $A$. elegans leaf extract on A549, HCT116 and HEPG2 was determined using MTS cell viability assay. Cancer cells $\left(5.0 \times 10^{3} /\right.$ well) were seeded into 96 -well plates, and the plates were incubated for $24 \mathrm{~h}$ at $37^{\circ} \mathrm{C}, 5 \% \mathrm{CO}_{2}$ to allow attachment. The cells were treated with various concentrations of A. elegans leaf extract (500 ppm, 250 ppm, 125 ppm,
$62.5 \mathrm{ppm}, 31.25 \mathrm{ppm}$ ), positive control doxorubicin (100 ppm, 50 ppm, 25 ppm, 12.5 ppm; Adrosal, Naprod Life Sciences), or negative control 0.1\% DMSO in culture media. After incubation for 48 and 72 hours at the same conditions, $10 \mu \mathrm{L} 5 \mathrm{mg} / \mathrm{mL}$ CellTiter $96^{\circledR}$ AQueous One Solution reagent (Promega) containing the tetrazolium compound 3-(4,5-dimethylthiazol-2yl)-5-(3-carboxymethoxyphenyl)-2-(4-sulfophenyl)-2Htetrazolium or MTS was added, followed by another $1 \mathrm{~h}$ incubation at $37^{\circ} \mathrm{C}, 5 \% \mathrm{CO}_{2}$. Absorbance was measured in triplicate at $492 \mathrm{~nm}$ using FLUOstar Omega Microplate Reader (BMG Labtech), and percent proliferation was calculated using the formula: $\%$ proliferation = (absorbance of treatment group / absorbance of negative control group) $\times 100$. A $\log [$ concentration]-response curve was constructed for both control and experimental groups, and the half-maximal inhibitory concentration $\left(\mathrm{IC}_{50}\right)$ for each treatment group was determined via probit analysis.

\section{Cytotoxicity assay}

To differentiate cytostatic from cytotoxic effects, $\mathrm{LDH}$ release assay was performed. Cancer cells $(5.0 \times 103 /$ well $)$ were seeded into 96 -well plates and were treated with various concentrations of $A$. elegans leaf extract (500 ppm, 250 ppm, $125 \mathrm{ppm}$ ), positive controls 5-fluorouracil (500 ppm; Fucil, Beacon Pharmaceuticals) and 10X lysis solution included in CytoTox $96{ }^{\circledR}$ Non-Radioactive Cytotoxicity Assay kit (Promega), or negative control $0.1 \% \mathrm{DMSO}$ in culture media. After incubation for 6 hours at $37^{\circ} \mathrm{C}, 5 \% \mathrm{CO}_{2}$, the plates were centrifuged at $2,500 \times \mathrm{g}$ for 5 minutes. Thirty microliters of supernatant were then transferred into a round-bottom 96-well plate, and the same amount of substrate mix containing the tetrazolium compound iodonitrotetrazolium violet or INT was added. The plates were incubated in the dark for 30 minutes, after which $30 \mu \mathrm{L}$ stop solution included in the assay kit was added into each well. Absorbance was measured in triplicate at $490 \mathrm{~nm}$ using FLUOstar Omega Microplate Reader (BMG Labtech), and percent cytotoxicity was calculated by using the absorbance values in the formula: \% cytotoxicity $=(($ treatment group - negative control group) / (lysis buffer control group - negative control group) $\times 100$, with absorbance of lysis buffer control group accounting for maximum LDH release, and absorbance of negative control group accounting for spontaneous LDH release. The half-maximal lethal concentration $\left(\mathrm{LC}_{50}\right)$ for the experimental treatment group was determined via probit analysis.

\section{Scratch wound assay}

In screening for metastatic potential, in vitro scratch wound assay was done. Cancer cells $\left(5.0 \times 10^{4} /\right.$ well $)$ were seeded into 96-well plates, and the plates were incubated for $24 \mathrm{~h}$ at $37^{\circ} \mathrm{C}, 5 \% \mathrm{CO}_{2}$ to allow attachment. The cell monolayer was scratched with a sterile white pipette tip and washed with $1 \mathrm{X}$ phosphate-buffered saline $\mathrm{pH}$ 7.4 to remove detached cells. The cells were treated with various concentrations of $A$. elegans leaf extract (500 ppm, 250 ppm, 125 ppm, 62.5 ppm, 31.25 ppm), positive control doxorubicin (10 ppm; Adrosal, Naprod Life Technologies), or negative control $0.1 \%$ DMSO in culture 
media. Brightfield images of the same gap area were captured in 1-hour intervals for 16 hours using Olympus IX83. Percent gap was computed as the area void of cells over total area using TScratch software version 1.0, and percent gap closure, an indicator of rate of cell migration, was calculated using the formula: $\%$ gap closure $=[((\%$ gap at $\mathrm{t}=0 \mathrm{~h})-(\%$ gap at $\mathrm{t}=16 \mathrm{~h})) /(\%$ gap at $\mathrm{t}=0 \mathrm{~h})] \times 100$.

Visualization of actin cytoskeleton and nucleus via fluorescence microscopy

Cancer cells $(5.0 \times 103 /$ well $)$ were seeded into 96well plates, and the plates were incubated for $24 \mathrm{~h}$ at $37^{\circ} \mathrm{C}, 5 \% \mathrm{CO} 2$ to allow attachment. The cells were then treated with $500 \mathrm{ppm}$ A. elegans leaf extract, or negative control $0.1 \%$ DMSO in culture media. Twenty-four hours post-treatment, the cells were washed with $1 \mathrm{X}$ PBS, and fixed with $50 \mu \mathrm{L} 4 \%$ paraformaldehyde for 5 minutes. Each well was washed twice to remove the fixative, and the cells were subsequently permeabilized using $100 \mu \mathrm{L}$ $0.1 \%$ Triton X-100 (Sigma Aldrich) in $1 \mathrm{X}$ PBS for 5 minutes. Afterwards, the cells were blocked with $50 \mu \mathrm{L}$ $1 \%$ bovine serum albumin in $1 \mathrm{X}$ PBS for 30 minutes. The cells were stained in the dark with $50 \mu \mathrm{L} 0.165 \mu \mathrm{M}$ AlexaFluor ${ }^{\circledR}-488$ phalloidin (Life Technologies) for 30 minutes. Each well was then washed with $1 \mathrm{X}$ PBS and counterstained with $100 \mu \mathrm{L} 1 \mu \mathrm{g} / \mathrm{mL}$ Hoechst 33342 (Thermo Scientific) for 5 minutes. The stained cells were mounted in $70 \%$ glycerol in $1 \mathrm{X} \mathrm{PBS}$, and were observed with green fluorescent filter ( $\lambda$ ex/ $/$ em: $490 / 525 \mathrm{~nm})$ and blue fluorescent filter ( $\lambda \mathrm{ex} / \lambda \mathrm{em}: 355 / 465 \mathrm{~nm})$ to visualize the stained filamentous actin structures and nuclei, respectively, using Olympus IX83.

\section{Statistical analyses}

All results were expressed as mean \pm standard error of the mean (SEM). One-way analysis of variance (ANOVA) test was performed with level of significance (a) set at 0.05 , followed by Tukey's multiple comparison test as post-hoc analysis. Differences were considered statistically significant at $p<0.05$. Statistical analyses were executed in GraphPad Prism version 8.4.0.

\section{Results}

A. elegans leaf extract exhibits anti-proliferative activity at high concentrations

Tetrazolium-based colorimetric assay is commonly used to assess cell viability by measuring the amount of tetrazolium salts reduced by live cells to colored formazan product. However, unlike the more commonly used MTT compound which yields insoluble precipitate, the formazan product of MTS compound readily dissolves in cell culture medium, thus removing the need for solubilization (Riss et al., 2013). A lower absorbance value measured in experimental groups compared to the negative control after 48-72 hours of incubation indicates a lower rate of cellular proliferation, suggestive of antiproliferative activity. As shown in Figure 1, TGK exhibited anti-proliferative activity at high concentrations compared to the positive control doxorubicin $\left(\mathrm{IC}_{50}, 72 \mathrm{~h}: 0.3685\right.$ to $6.698 \mathrm{ppm}$ ), which can be explained by the crudeness of
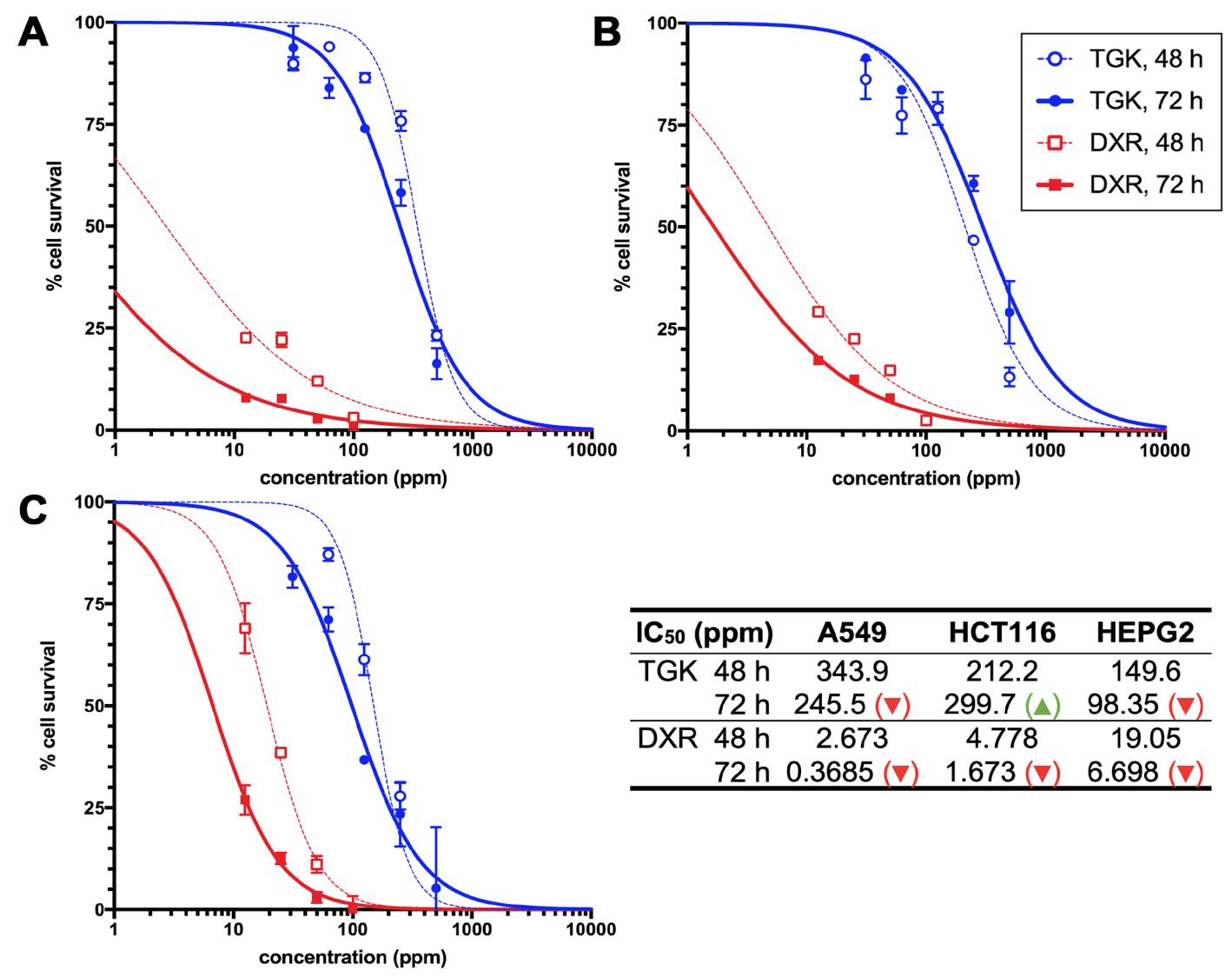

\begin{tabular}{rccc}
\hline IC $_{\text {50 }}(\mathbf{p p m})$ & A549 & HCT116 & HEPG2 \\
\hline TGK $48 \mathrm{~h}$ & 343.9 & 212.2 & 149.6 \\
$72 \mathrm{~h}$ & $245.5(\nabla)$ & $299.7(\Delta)$ & $98.35(\nabla)$ \\
\hline DXR $48 \mathrm{~h}$ & 2.673 & 4.778 & 19.05 \\
$72 \mathrm{~h}$ & $0.3685(\nabla)$ & $1.673(\nabla)$ & $6.698(\nabla)$ \\
\hline
\end{tabular}

Figure 1. MTS Cell Proliferation Assay on (A) A549, (B) HCT116, (C) HEPG2 Cells at 48 h (dotted line) and $72 \mathrm{~h}$ (Continuous Line) Following Exposure to Various TGK Concentrations. Positive control: doxorubicin (DXR) (red line). Data points are means \pm standard error of the mean (SEM). 

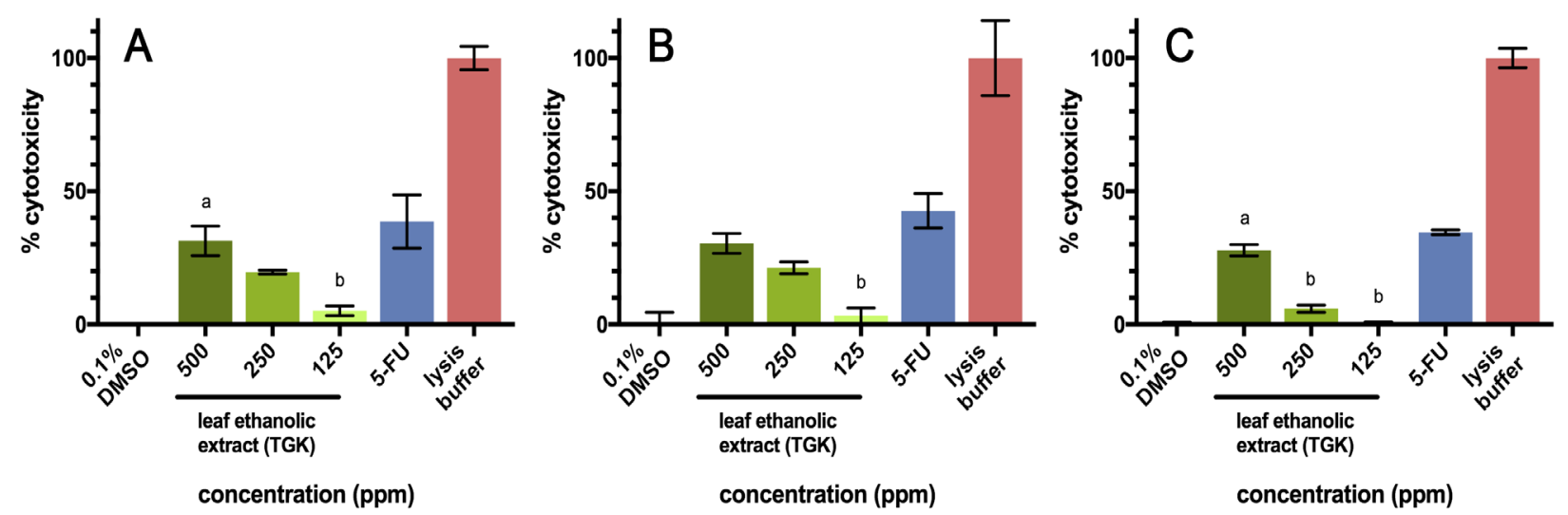

Figure 2. LDH Cytotoxicity Assay on (A) A549, (B) HCT116, (C) HEPG2 Cells Following Exposure to Various TGK Concentrations. Negative control: 0.1\% DMSO; positive control: 5-fluorouracil (5-FU). Statistical analysis: $\mathrm{a}-\mathrm{p}<0.05$ vs $0.1 \%$ DMSO; $\mathrm{b}-\mathrm{p}<0.05$ vs 5 -FU. Data points are means \pm standard error of the mean (SEM).

the extract. Phytochemical analysis revealed multitudes of phytochemicals, including traces of alkaloids, moderate amounts of sterols, and abundant triterpenes, flavonoids, saponins, glycosides and tannins, in the crude ethanolic
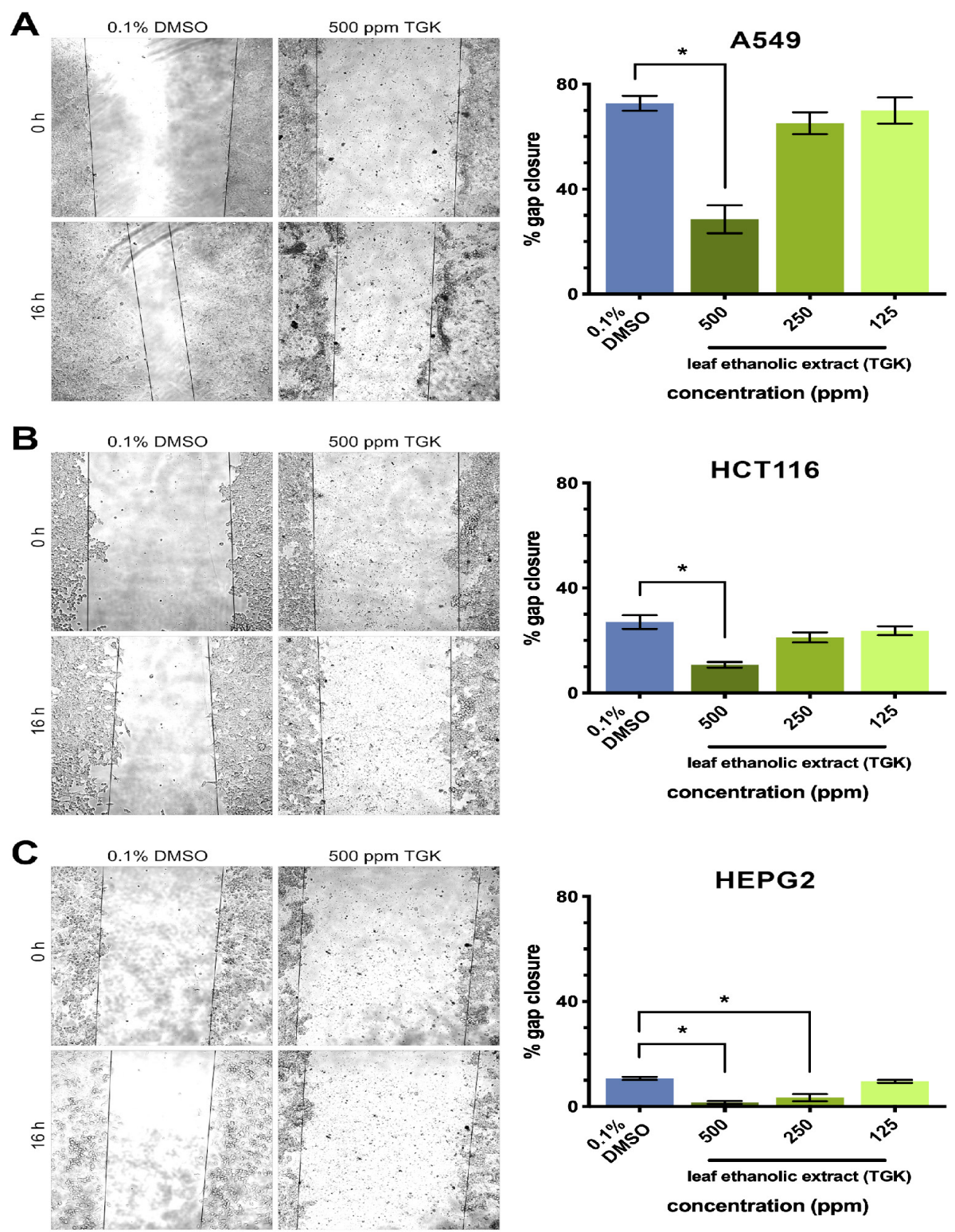

Figure 3. Scratch Wound Assay on (A) A549, (B) HCT116, (C) HEPG2 Cells Following Exposure to Various TGK Concentrations. Shown are representative images at $0 \mathrm{~h}$ and $16 \mathrm{~h}$, and the measured \% gap closure. Negative control: $0.1 \%$ DMSO. Statistical analysis: $* \mathrm{p}<0.05$. Data points are means \pm standard error of the mean (SEM). 

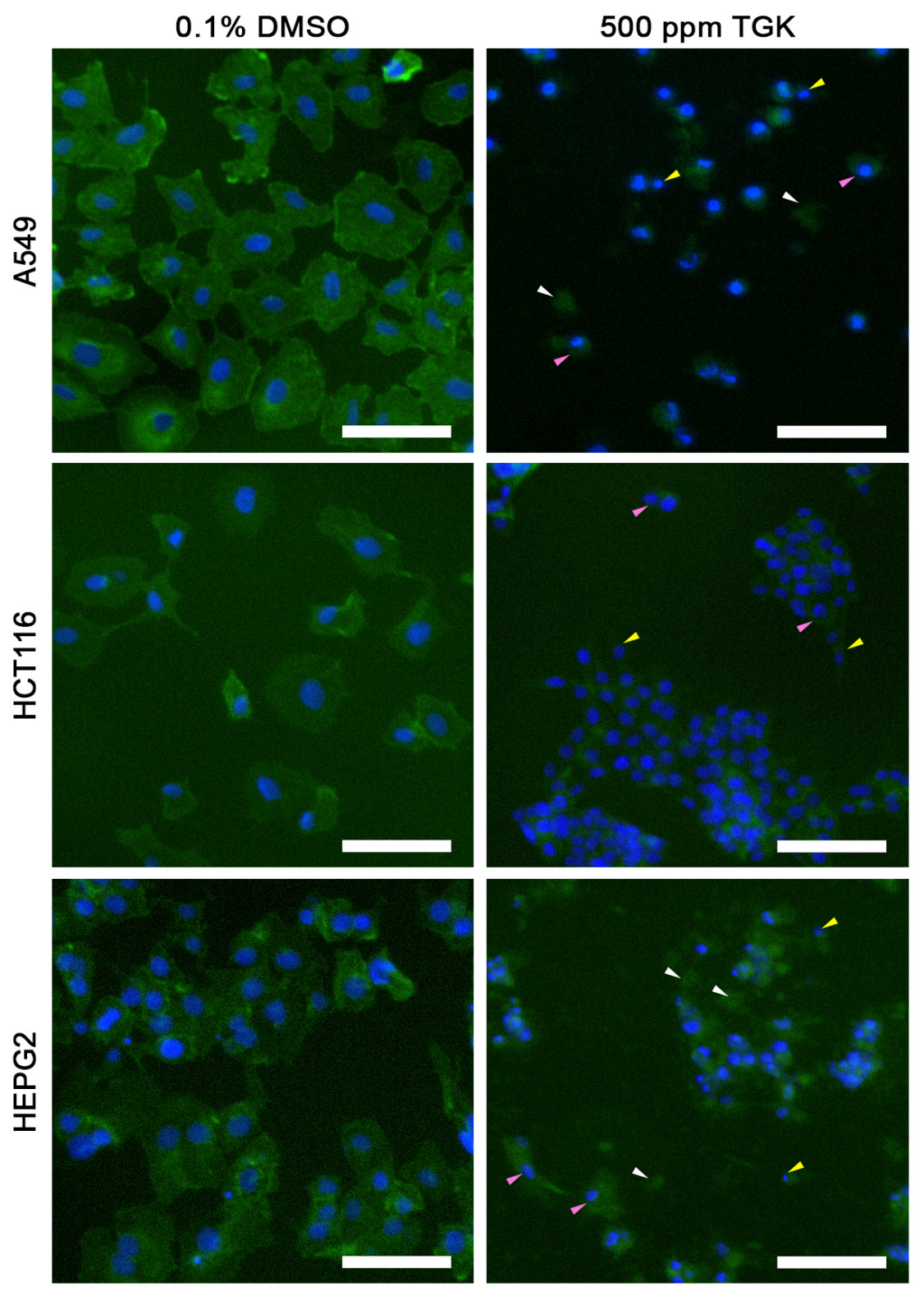

Figure 4. Visualization of Actin Filaments and Nuclei via Fluorescence Staining Following Exposure to 0.1\% DMSO (Negative Control) and 500 ppm TGK (Experimental Treatment). Legend: White arrowhead - cellular debris; yellow arrowhead - pyknosis (nuclear shrinkage); pink arrowhead - cellular shrinkage. Size of bar: $100 \mu \mathrm{m}$.

extract, thus diluting the concentration of bioactive compounds in TGK. The observed activity follows an inverse concentration-response relationship, in which the percent proliferation decreases with increasing extract concentration. TGK appears to be more effective against HEPG2 (IC50, 72h: 98.35 ppm) and A549 (IC50, 72h: $245.5 \mathrm{ppm}$ ) than HCT116 (IC50, 72h: $299.7 \mathrm{ppm}$ ). Moreover, the $\mathrm{IC}_{50}$ increases with increasing duration of exposure except for HCT116, which may be attributed to the metabolism of active components in the extract, as well as faster doubling time of HCT116 cells (Owa et al., 2014).

\section{Anti-proliferative effect of $A$. elegans leaf extract} attributed to its cytotoxicity

To determine if the anti-proliferative activity of TGK was due to its cytotoxic or cytostatic effects on the cells, LDH release assay was performed wherein LDH released from damaged cells convert the substrate INT into purple formazan. As shown in Figure 2, TGK appears to be more cytotoxic against HEPG2 ( $\mathrm{LC}_{50}, 6 \mathrm{~h}: 712.3$ ppm) and HCT116 (LC50, 6h: 920.3 ppm) than A549 $\left(\mathrm{LC}_{50}, 6 \mathrm{~h}: 906.8 \mathrm{ppm}\right)$. The observed activity follows a direct concentration-response relationship, in which the percent cytotoxicity increases with increasing extract concentration. At $500 \mathrm{ppm}$ TGK, the percent cytotoxicity was significantly different with $0.1 \%$ DMSO $(p<0.05)$, but not with 5-FU. These results suggest that the antiproliferative activity of TGK can be attributed mostly to its cytotoxic effect on cancer cells, comparable to 5-fluorouracil at high concentrations of TGK.

\section{A. elegans leaf extract inhibits cell migration at high concentrations}

An important indicator of metastasis, cell migration was also assessed via scratch wound assay, with percent gap closure after 16 hours as its indicator. As shown in Figure 3, the observed activity follows an inverse concentration-response relationship, in which rate of cell Asian Pacific Journal of Cancer Prevention, Vol $22 \mathbf{3 7 8 5}$ 
migration decreases with increasing extract concentration. The percent gap closure was significantly different with both $0.1 \%$ DMSO (negative control) and $10 \mathrm{ppm}$ doxorubicin (positive control) at $500 \mathrm{ppm}$ TGK $(\mathrm{p}<0.05)$ consistently across cell lines. This suggests that at high concentrations, TGK significantly inhibits cell migration, even better than the positive control. Although cytotoxicity partially explains suppression of cell migration, the bioactive components in the extract possibly also targeted lamellipodial extension, attachment, cell body translocation or cell retraction, which are coordinated processes responsible for cell migration (Mitra et al., 2005; Berrier and Yamada, 2007).

Apoptotic and necrotic morphological changes in cells exposed to A. elegans leaf extract

Fluorescence staining (Figure 4) showed that at 500 ppm TGK, cell shrinkage to at least $1 / 16$ of the original cell size, nuclear shrinkage or pyknosis to at least half the original nuclear length, and cellular debris were observed consistently across cell lines. Cell shrinkage and pyknosis are seen in early stages of apoptosis, while cell swelling and plasma membrane rupture leading to cellular debris are mostly associated with necrosis (Kerr et al., 1972; Raffray and Cohen, 1997). These results show that the morphological changes seen in cancer cells after exposure to high TGK concentration are consistent with both apoptosis and necrosis, which explain the inhibition of both cell proliferation and migration.

\section{Discussion}

Many studies have been published regarding anti-cancer potential of various plant extracts which can be good candidates for cancer drug discovery and development, an example of which is the approval of paclitaxel isolated from Taxus brevifolia for chemotherapeutic use (Liebmann et al., 1993). In particular, closely related species of Alpinia elegans have been shown to have anti-cancer activity in vitro. Chloroform extract of $A$. scabra leaves was found to induce apoptosis in MCF-7 breast and SKOV-3 ovarian carcinoma cells (Reddy et al., 2013). Ethanolic extract of A. galanga rhizomes also induced apoptosis in MCF-7 cells, while aqueous extract of whole $A$. galanga plants inhibited cell proliferation of AGS gastric adenocarcinoma cells (Samarghandian et al., 2014; Afshari et al., 2008). Pinostrobin chalcone and alpinetin isolated from $\mathrm{A}$. mutica rhizomes showed significant cytotoxic activity against MCF-7 breast and CaSki cervical carcinoma cells (Riss et al., 2013).

As of writing, only one other study has looked into the potential anti-cancer activity of $A$. elegans, which has been used as medicinal plant for hemoptysis and urticaria (Quisumbing, 1978) with evidence of anti-microbial properties (Oliveros and Bruce, 1991), and as natural insect pest maanagement in rice fields (Calumpang et al., 2013). Volatile plant-derived products from essential oil of $A$. elegans rhizomes have been shown to have cytotoxic activity in Caco-2 colon cancer cells (Houdkova et al., 2020). This study, the first done in A. elegans leaves, showed anti-cancer activity against A549 lung, HCT116 colorectal and HEPG2 hepatocellular carcinoma cells, although at high concentrations of crude leaf ethanolic extract. Its anti-oxidant property may partly explain the observed anti-cancer activity in the human cancer cell lines as shown by high 1,1-diphenyl-2-picrylhydrazyl (DPPH) radical scavenging activity of the leaf ethanolic extract in a previous study (Naive et al., 2019). Based on National Cancer Institute (NCI), an $\mathrm{IC}_{50}$ value of less than $30 \mathrm{ppm}$ is an indicator of significant activity against cancer cell lines (Suffness and Pezzuto, 1990), with none of the $\mathrm{IC}_{50}$ values for the leaf extract falling within this value, which may be a consequence of using crude ethanolic extract, which is a major limitation of this study.

Most cancer chemotherapeutic agents target malignant cells through apoptosis and/or necrosis (Mahassni and Al-Reemi, 2013). The induction of apoptosis and necrosis in cancer cells by A. elegans leaf ethanolic extract may be favorable in vivo because the inflammatory necrotic environment would attract immune cells in the tumor site, while apoptotic induction would allow modulation of programmed cell death in cancer cells. Although elucidation of molecular targets and pathways is needed, the findings in this study show the potential of A. elegans as alternative anti-cancer treatment.

In conclusion, this study shows that the ethanolic leaf extract of Alpinia elegans significantly inhibits cellular proliferation and migration, albeit at high concentrations, with direct exposure-response relationship within concentrations. It also shows both hallmarks of apoptosis and necrosis as mechanism for the extract's cytotoxic activity at high concentration. To ensure that the cytotoxic activity is specific to cancer cells, it is recommended to isolate the bioactive compounds in the leaf extract and to explore activity on other hallmarks of cancer such as angiogenesis.

\section{Author Contribution Statement}

RCVL and PMBM conceptualized and designed the study; RCVL performed the experiments and collected the data; RCVL and PMBM analyzed and interpreted the results; RCVL prepared the initial manuscript; RCVL and PMBM reviewed and approved the final version of manuscript.

\section{Acknowledgements}

The authors would like to express their gratitude to Dr. Isidro Sia of Department of Pharmacology and Toxicity, College of Medicine, University of the Philippines Manila for sharing his expertise on medicinal plants, and Dr. Susan Calumpang of National Crop Protection Center, University of the Philippines Los Baños for providing us with $A$. elegans samples. Special thanks is given to the Disease Molecular Biology and Epigenetics Laboratory of National Institute of Molecular Biology and Biotechnology - University of the Philippines Diliman under Dr. Reynaldo Garcia for the technical assistance in this project. Financial support is provided via the Student Research Support Fund of Philippine Department of 
Science and Technology - Philippine Council for Health Research and Development (DOST-PCHRD). This study was approved by the Technical Review Board of the Department of Biochemistry and Molecular Biology, College of Medicine, and was exempt from ethical review by the Research Ethics Board, both under University of the Philippines Manila.

\section{Conflict of interests}

Both authors have no conflicts of interests to disclose.

\section{References}

Afshari JT, Zade MH, Barati M (2008). Evaluation the effect of water extract of Alpinia galanga L. on inhibition of the HT-29 colorectal cancer cell Lines and rat fibroplast non-cancer cell line (L929). J North Khorasan Univ Med Sci, 1, 47-58.

Berrier AL, Yamada KM (2007). Cell-matrix adhesion. J Cell Physiol, 213, 565-73.

Calumpang SMF, Burgonio GAS, Navasero MM, Navasero MV (2013). Behavioral and olfactory responses of rice green leaf hopper, Nephottetix virescens (Distant) to volatile cues from tagbak (Alpinia elegans (C. Presl) K. Schum). Philipp $J$ Sci, 142, 167-73.

Houdkova M, Albarico G, Doskocil I, et al (2020). Vapors of volatile plant-derived products significantly affect the results of antimicrobial,antioxidative and cytotoxicity microplatebased assays. Molecules, 25, 6004.

International Agency for Research on Cancer (2018). Cancer Today. Accessed April 1, 2021. https://gco.iarc.fr/today/ home.

Kerr JF, Wyllie AH, Currie AR (1972). Apoptosis: A basic biological phenomenon with wideranging implications in tissue kinetics. Br J Cancer, 26, 239-257.

Laudico AV, Mirasol-Lumague MR, Medina V, et al (2015). Philippine Cancer Facts and Estimates. Philippine Cancer Society, Manila.

Liebmann J, Cook J, Lipschultz C, et al (1993). Cytotoxic studies of paclitaxel (Taxol®) in human tumour cell lines. Br J Cancer, 68, 1104-.

Mahassni SH, Al-Reemi RM (2013). Apoptosis and necrosis of human breast cancer cells by an aqueous extract of garden cress (Lepidium sativum) seeds. Saudi J Biol Sci, 20, 131-9.

Malek SNA, Phang CW, Ibrahim H, Wahab NA, Sim KS (2011). Phytochemical and cytotoxic investigations of Alpinia mutica rhizomes. Molecules, 16, 583-9.

Mitra SK, Hanson DA, Schlaepfer DD (2005). Focal adhesion kinase: In command and control of cell motility. Nat Rev Mol Cell Biol, 6, 56-68.

Naïve MAK, Dalisay JAGP, Maglangit EPT, Cafe GC, Nuñeza OM (2019). Free radical scavenging effects of the Philippine endemic medicinal plant Alpinia elegans (Zingiberaceae). Gard Bull Singapore, 71, 435-44.

Oliveros MB, Bruce BE (1991). Studies on the antimicrobial properties of Zingiber purpureum Rosc. and Kolowratia elegans Presl. (Family Zingiberaceae). Plant Physiol Biochem, 42, 267-87.

Owa T, Ozawa Y, Semba T (2014). U.S. Patent No. 8,772,269. U.S. Patent and Trademark Office, Washington, D.C.

Quisumbing E (1978). Medicinal plants of the Philippines. Katha, Quezon City.

Raffray M, Cohen GM (1997). Apoptosis and necrosis in toxicology: A continuum or distinct modes of cell death? Pharmacol Ther, 75, 153-77.

Reddy AS, Malek SNA, Ibrahim H, Sim KS (2013). Cytotoxic effect of Alpinia scabra (Blume) Náves extracts on human breast and ovarian cancer cells. BMC Complement Altern Med, 13, 314.

Riss TL, Moravec RA, Niles AL, et al (2013). Cell viability assays. In 'Assay guidance manual', Eds Sittampalam GS, Coussens NP, Brimacombe K, et al. Eli Lilly \& Company and National Center for Advancing Translational Sciences, Besthesda, MD.

Samarghandian S, Hadjzadeh MAR, Afshari JT, Hosseini M (2014). Antiproliferative activity and induction of apoptotic by ethanolic extract of Alpinia galanga rhizhome in human breast carcinoma cell line. BMC Complement Altern Med, 14, 192.

Suffness M, Pezzuto JM (1990). Assays related to cancer drug discovery. In 'Methods in Plant Biochemistry: Assays for Bioactivity', vol. 6, Ed Hostettmann K. Academic Press, London.

World Health Organization (2004). New WHO guidelines to promote proper use of alternative medicines. Accessed April 1, 2021. https://who.int/mediacentre/news/releases/2004/ pr44/en/.

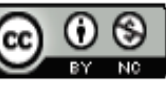

This work is licensed under a Creative Commons AttributionNon Commercial 4.0 International License. 